

\section{Green Infrastructure for Landscape Planning: integrating human and natural}

systems, by Gary Austin, Oxford, Routledge, 2014, 266 pp., f37.99 (hardback), ISBN 978-0-415-84353-9

Green infrastructure is a deceptively simple idea. It advances an intuitive planning and design perspective on how ecosystems health is a prerequisite for human well being. However, the rapidly emerging field of green infrastructure theory and practice is a noisy place of multiple definitions, foci and disciplinary languages which frequently swamps the concept in complexity and confusion. Gary Austin's new book presents an admirable effort to cut through this cacophony by organising and integrating a bewildering variety of views into a coherent exposition of 'what' green infrastructure is, 'why' it should be promoted, and 'how' it can be advanced in planning and design activities. Consequently, this book provides a valuable contribution to planning, urban design and landscape architecture.

As both a synthesis of current thinking and an original contribution to knowledge of the topic, the book is most suitable for an academic and practitioner readership of planners and designers. In general, Austin advances a distinctive North American inflection that presumes a USA based audience. Nevertheless, the book's global survey of best practice compensates for this and ensures its usefulness to an international readership. The book is implicitly structured in five sections: an introduction; a justification for the green infrastructure approach; the specifics of green infrastructure planning and design; an illustrative case study; and a conclusion. Unfortunately, the failure to make this structure explicit in the contents page inhibits ease of navigation for the range of potential readers who may approach the book for different reasons. However, the discrete yet related format of each chapter allows the reader to consult the sections of most interest to them without losing the broader argument advanced by the text in its entirety.

Chapter 1 provides an excellent introduction to the subject. Austin emphasises the need to fuse ecocentric and anthropocentric value frames in fashioning more ecologically sensitive planning and design activities that enhance biodiversity while concurrently providing ecosystems services to society. In this sense, green infrastructure is presented as a multi-scalar 'systematic, holistic approach, involving transdisciplinary cooperation' (p.3) for delivering networks of multifunctional 
open spaces. Also offered here is a brief history of green infrastructure thinking, although this is strongly accented by a focus on developments in the USA. Chapters 2, 3 and 4 provide an extended justification as to why green infrastructure planning and design is necessary. Chapter 2 is a useful and well referenced chapter that addresses the physical and psychological health benefits of green infrastructure. Austin's decision to foreground such issues is a refreshing contrast to most literature on the topic, which prioritise ecosystems conservation and ecosystems services. However, at times the author overloads the reader with unnecessary data in seeking to substantiate the logic for considering such issues in planning and design. Presenting this information in tabular form and directing the interested reader to specific references would have sufficed without reducing the argument's impact. The relative merit of such an approach is illustrated by Chapter 3 which offers a more accessible introduction to the complex attributes and interactions governing ecosystem functions and health. Chapter 4 then structures a comprehensive and coherent discussion of ecosystems services around the supporting, regulating, provisioning and cultural categories of anthropocentric benefit specified in the United Nation's Millennium Ecosystems Assessment.

Having thus outlined 'why' it is important, the author subsequently details 'how' to design the various elements of green infrastructure. Chapter 5 commences this exposition with an account of the crucial intersections between planning and design processes in the delivery of green infrastructure. Austin approaches this by examining both the administrative and technical design aspects of green infrastructure. The chapter is well illustrated with numerous case study examples but suffers from a disproportionate focus on the USA. Where international exemplars are referenced, this is done so with respect to contrasting experiences in North America. Such an imbalance curbs the potential of this chapter to inform planning activities beyond the USA. The author seems more confident in chapters 6 through to 9 where issues of ecological corridors, open space networks, stormwater management and green roofs are respectively considered. As a whole, these chapters provide a valuable resource for those interested in the design technicalities of green infrastructure. Taken separately, each chapter is individually beneficial for the researcher or practitioner seeking to deepen their knowledge of a specific aspect of green infrastructure design. Austin seems especially at home with stormwater management and treatment systems, the discussion of which offers a description, justification and virtual manual for the designer. Chapter 10 provides food for thought in a short but engaging discussion on how community 
agriculture can be integrated into green infrastructure planning and design. The author once again displays his design proficiency in Chapter 11, where the physical, biological and chemical requirements of wastewater treatment wetlands are detailed through text, tables, diagrams and photos. While this chapter primarily outlines the benefits and technicalities of constructing wastewater wetlands, Austin is careful to stress how careful planning can ensure that such schemes facilitate the simultaneous provision of multiple services, such as biodiversity enhancement and recreational space provision. Chapter 12 ties together the preceding argument through a well illustrated case study of green infrastructure implementation in Stockholm. Of particular note is how Austin successfully manages an investigation into the multi-scalar dimensions of planning by demonstrating how Stockholm has effectively integrated the regional, municipal and neighbourhood scales of design to deliver a spatially extensive multifunctional green infrastructure network. The book closes at Chapter 13 with a brief conclusion that seeks to relate to a North American context the lessons learned from the earlier survey of international best practice. In a useful distillation of the principles discussed throughout the text, the book ends with a 'demonstration plan' of an archetypal green infrastructure scheme.

An admirable feature of Austin's approach is how he seamlessly weaves case studies throughout the text to substantiate and illustrate the assertions made. The extensive referencing of contemporary studies is also commendable as it allows the reader to explore in greater depth the latest thinking on specific aspects of green infrastructure planning and design. The abundant colour photos and illustrations both enliven the text and help convey the book's message on how 'the implementation of multifunctional components of a green infrastructure network will lead to a future of economic, environmental and social health' (p. 225). Consequently, this book supplies an indispensable resource for the academic or practitioner seeking current knowledge on the quickly evolving field of green infrastructure planning and design.

Mick Lennon

School of Geography, Planning and Environmental Policy,

University College Dublin, Ireland michael.lennon@ucd.ie 